\title{
Contamination Levels of Some Selected Wells in Ogbomoso South Local Government Area, Nigeria and the Implications on Human Health
}

\author{
Samson O. Ojoawo*, T. Lateef Kolade \\ Department of Civil Engineering, Ladoke Akintola University of Technology, Ogbomoso, Nigeria \\ Email: "soojoawo@lautech.edu.ng
}

Received April 15, 2013; revised May 22, 2013; accepted June 18, 2013

Copyright (C) 2013 Samson O. Ojoawo, T. Lateef Kolade. This is an open access article distributed under the Creative Commons Attribution License, which permits unrestricted use, distribution, and reproduction in any medium, provided the original work is properly cited.

\begin{abstract}
Incident of water-borne diseases is becoming more rampant in developing countries in the $21^{\text {st }}$ century. This paper examines the contamination levels of some selected wells in Ogbomoso South Local Government Area (LGA), Oyo State, Nigeria. Methodology includes administering of structured questionnaire, field survey/sampling and laboratory analysis. The first set of questionnaires sought information on water sources, quality, supply and treatment. These were administered in 10 selected major locations which included: Ajegunle, Arinkinkin, Arowomole, Caretaker, Esanu-Aje, Ita-Olola, Malete, Oke-Alapata, Ora-Gada and Sunsun. The other set which was administered in 6 randomly selected Health Institutions viz: Oyo State General Hospital, Alaafia Tayo, Oore-Ofe, Bethel, Favour, and Grace Hospitals had questions on health-related issues. Ten (10) wells were randomly selected for sampling, one in each location. Results were compared with WHO’s Drinking Water Standards. Questionnaires revealed that residents depended mostly on wells for water supply; the water quality was low; supply was irregular; quantity was inadequate and boiling was the commonest treatment method. Health Officials established that some residents consumed improperly treated well water and there were some incidences of water-related diseases. Laboratory analyses showed that samples from Ajegumle and EsanuAje had colour values above the standard. Also, the $\mathrm{pH}$ was observed to vary from slightly acidic to slightly alkaline with values ranging between 6.0 and 8.1. Only Arinkinkin and Ita-Olola areas had permissible values of total alkalinity and Oke-Alapata had the highest chloride value of $400 \mathrm{mg} / \mathrm{l}$ while the highest nitrate concentration was at Esanu-Aje $(127.58 \mathrm{mg} / \mathrm{l})$. Study concludes that water supply in the area is not fully supportive to health. To abate the problem, it is recommended that aside boiling, each household should endeavour to coagulate, filter, soften and disinfect well water before consumption. Also, personal hygiene within each household must always be emphasized and improved upon.
\end{abstract}

Keywords: Contamination; Wells; Water Quality; Human Health

\section{Introduction}

The importance of water to man cannot be over-emphasized. It forms about 70 per cent of our body fluids and serves many other purposes among which are: drinking and culinary uses, washing, bathing and laundering, watering lawns and gardens, protecting life and property against fire, etc. People in the rural areas in absence of potable water are exposed to the risk of water borne diseases like cholera, typhoid and other environmental implications [1]. There is evidence of widespread contamination of water resources in many areas of Nigeria. The Environmental Protection Agency's National Water Qua-

*Corresponding author. lity Inventory of 1994 has identified agriculture, urban runoff/storm water, and municipal point sources of the largest pollutant sources for rivers, lakes, and estuaries. Contaminants from these sources include pesticides, metal, nitrates, solvents, and other wastes. It should however be noted that not all contamination events pose a threat to our health [2].

Water resources normally refer to the whole of the waters of a territory which can be used for supporting the diverse needs of individuals and communities [3]. Resources are all the attributes of our natural environment that can be utilized to promote human welfare at any place at a point in time. Resources vary in quantity, quality, mutability, renewability, reusability and availability. 
The continued availability of adequate fresh water resources is a pre-requisite for sustaining life and development. It is imperative to plan and monitor the nation's water resources to achieve sustainable development of the vital resources especially in the face of changing climate. The development plan of water supply systems is important and must account the available water as a resource which should be well developed planned and exploited in order to obtain maximum returns at minimum cost.

The major sources of water pollution are sewage or untreated faecal matter, domestic and industrial solid waste, sullage, and industrial waste water and sediment from soil erosion [4]. Sewage effluent and faeces when properly treated poses minimal pollution or health problems though they require heavy financial investment but the advantage is greater than the cost. Domestic and industrial solid wastes are found floating on rivers this pollutes the water and constricts the water flow. This eventually results in flooding which destroys lives and property. Sullage and industrial wastewater often contain significant amount of phosphate and oils and they constitute significant sources of water pollution. It is unfortunate that industrialization does not only increase human comfort but also spell doom on man. In an earlier work in South-Southern Nigeria, [5] reported that chemical characteristics including Nitrate oil and grease and metals like $\mathrm{Fe}, \mathrm{Pb}$ and $\mathrm{Ni}$ exceeded the acceptable limits in some or most of the wells sampled and this could portend serious health problems. This observation was more obvious around the refinery and water-side areas of Warri. Sediment of soil erosion is another source of pollution especially in the place where agriculture is being practiced. In sloppy areas it is easy by gravitational force for liquid to spread to a wide expanse area of land.

When a contaminant first enters the soil it will travel down vertically gravity until contact with groundwater. At this point it will begin to floor primarily in a horizontal direction. The contaminants will then spread out three-dimensionally like smoke from a chimney and is called a plume. Groundwater does not exhibit turbulent flows as found in surface water. The flow is defined by gravity, pressure and friction. It is much more constant than surface water. An aquifer can flow at a fraction of an much per day up to few of reducing contaminants in drinking water by controlling it at the source. Preventative measures such as modification of tilling methods and run-off, control in agriculture, the use of lined catchment ponds for treatment of wastes, and double lined underground storage tanks can greatly reduce contamination of drinking water sources [2].

Wells are one of the oldest sources of water. In many rural areas, wells are the only reliable water sources while in most cases; well water is a safe and dependable option, in rare instances where contamination has occurred. A well can be contaminated by disease-producing pathogens and leachates from disposal of hazardous household wastes [6]. The level of contaminant in drinking water is sometimes high enough to cause acute (immediate) health effects such as nausea, lung irritation, skin rash, vomiting, dizziness, and even death. And more so, contaminants are more likely to cause chronic health effects occurring long after repeated exposure to small amount of a chemical. Examples of chronic health effects include cancer, liver and kidney damage, disorder and damage of the nervous system, damage to the immune system and birth defects [7]. Evidence relating chronic health effects to specific drinking water contaminants is limited. In the absence of exact scientific information, scientists predict the likely adverse effects of chemicals in drinking water using human data from clinical reports and epidemiological studies, and laboratory animal studies. Radon is a radioactive contaminant that results from the decay of uranium in soils and rocks. It is usually more of a health concern when it enters a home as a gas than when it occurs in water supplies. Radon in air is associated with the possibility of contaminant in drinking water. Water supplies once considered to be pure may have various contaminants, often from natural sources these are usually at levels below those considered to be harmful.

Water systems can be sensitive barometers of the health of the planet. Decreased fresh water supply has encumbered world food harvest, destroyed precious aquatic habitats and threatened biodiversity. WHO in 1985 estimated that $80 \%$ of all sickness and diseases in the world are attributable to unhygienic water. Water borne diseases are among the leading causes of death in many developing countries $10 \%$ of their productive time because of diseases related to poor and contaminated water programmes. Water from any sources must suit the purpose for which it is intended. Good quality water is water that is safe to use. Water intended for drinking must be free from pathogenic organisms. The chemical and physical qualities must also be suitable. Water must not contain any dissolved or suspended materials that are injurious to health of that would give an unpleasant taste. Physically safe water must be at suitable temperature and not have objectionable colour or cloudiness [8]. The quality of water according to [10] comprises consideration of many different factors. Information on and control of water quality is of great importance for a wide range of purpose including water supply, public health, agricultural and industrial uses.

As a result of human activities especially in urban areas toxic materials discharged into the environment have affected the quality of water and rendered it unsafe. Good management of waste from households industries and 
automobiles will safe-guard water contamination by improving its quality. Dissolved gases in water such as carbon-dioxide $\left(\mathrm{CO}_{2}\right)$ methane $\left(\mathrm{CH}_{4}\right)$ and Hydrogen Sulphide, for example at concentration greater than $1 \mathrm{mg} / \mathrm{l}$ are unfit for human consumption [9]. The World Health Organization has set standards for water quality. This serves as a basis for approval of results of chemical analysis of in terms of suitability of water for various intended uses. A recent one is those established for drinking water in Geneva 2011. To date there is considerable controversy with regard to the specific organic constituents that should be included in drinking water standards and concentration limits that should be established. For example total dissolved solids, Sulphate and Chloride consumption by humans thought water having concentration above WHO 2011 limits is not generally harmful [10]. Most often water when it is related to health laid more emphasis on the water chemistry this may be due to the fact that the world around us is made up of chemicals. In the bid to improve water quality disinfect water or our immediate environment and improvement in quality of living has resulted to introduction of toxic chemicals directly and indirectly to water available for our uses. Lead, Arsenic and Mercury are known to be harmful to humans even in small account. Also excessive Nitrates $\left(\mathrm{N}-\mathrm{NO}_{3}\right)$ cause metheno-globinemia in infants at a range more than 15 - $25 \mathrm{mg} / \mathrm{l}$, it can affect livestock as well and can result in certain form of cancer [11]. Uses of chemical to disinfect water require skill and experience otherwise its shortage of required quantity leave the water partially treated with the disease causing organism in the water increasing their resistant to such treatment. Over dosage will also have side effects, for instance excess iodine in water causes goitre, while potassium permanganate adds colour to water and stains materials.

Beside chemical elements in water, microbiological organisms as well as physical characteristics and radiological materials have their effects on health. The microbiological quality of water determines and helps in diagnosing various forms of diseases that can be linked to water either for its transmission sustenance or eradication. Drinking water should not contain pathogenic microorganism, and should be free of bacteria that indicate excremental pollution. Water to be used for washing, bathing and cooking as well must be free of pathogens carrying contagious diseases. It is therefore important that drinking water and house-hold use water samples from source to storage vessels be tested regularly for possible indicators of dangerous microbiological organisms. Such indicators include faecal streptococci, clostridium welchi and the coliform aerogens group; all these indicators are excreted in large numbers from warm blooded animals and their detection in water-denoted faecal pollution. Some macroscopic biological organism through their life cycle or activities especially aquatic lives contributes to health impacts of water on human being. Larvae crustacea and large numbers algae or filamentous growth (i.e. spirogyra) should not be allowed in house-hold use water. They affect taste, odour and appearance of water. Good water for domestic use must be free of disease-carrying organisms like bacteria-cholera and typhoid, protozoaamoebic dysentery, viral infections hepatitis, worms-guinea worn, angus-ring worm of the foot, etc. Moreover, radiological materials are harmful; therefore their intake should be kept to a minimum. Radium and Strontium are particularly harmful when taken internally. Emission of radioactive materials gets into water unconsciously wherever it is used. In hospitals where it is used for X-Ray and curing of other ailments the storage vessel even water pipes made of metal not to mention plastics pipes can be penetrated by radioactive materials.

Anchored on various records of water-related health crises being noted in the Ogbomoso South Local Government (OSLG) Area, this research work focuses on the investigation of the contamination levels of some selected wells in the area and studying their associated health implications on human beings. With the present dearth of information on such occurrences in the study area, a study of this nature is expected to provide technical explanations on the causes and implications of these incidents of water-borne diseases on human health. The OSLG has an area of $68 \mathrm{~km}^{2}$ and with a population of 100,815 people [12]. With increase in agricultural activities and domestic chores in the area, there is greater need for the adequate supply of good quality water for the growing population. As the well water is naturally provided to every being, and then the environmental and health implications that were attached to this natural resource cannot be over emphasized. This research therefore ultimately targets minimizing the deleterious effects associated with the consumption of contaminated well water.

\section{Methodology}

\subsection{Structured Questionnaire}

Two different sets of questionnaires were prepared according to the National Environmental Standard Regulation and Enforcement Agency (NESREA) guidelines format. The first set sought information which bothered on water sources, its quality, supply and treatment were administered in 10 selected major locations in the LGA which include: Ajegunle, Arinkinkin, Arowomole, Caretaker, Esanu-Aje, Ita-Olola, Malete, Oke-Alapata, OraGada and Sunsun. The other set which was administered in the six (6) randomly selected Health Institutions in the LGA viz: Oyo State General Hospital, Alaafia Tayo, 
Oore-Ofe, Bethel, Favour, and Grace Hospitals have questions on water borne-diseases and health-related issues.

\subsection{The Sampling}

Ten (10) wells were randomly selected, one in each major locations in the LGA viz: Ajegunle, Arinkinkin, Arowomole, Caretaker, Esanu-Aje, Ita-Olola, Malete, Oke-Alapata, Ora-Gada and Sunsun. One (1)-litre plastic containers were used to collect the water samples from the well visited. The containers were thoroughly washed in the laboratory with distilled water and labeled accordingly. At the sampling point, the containers were again rinsed with the samples to be collected.

\subsection{Laboratory Analysis of Samples}

The well water samples collected were taken directly to the laboratory without any preservation for the physical and chemical analysis. The parameters of interest and their tests are as follows:

1) Temperature: This was carried out with the aid of a thermometer in situ while taking the samples.

2) $\mathbf{p H}$ : Some quantities of the water sample were poured into the beaker and the electrode of the $\mathrm{pH}$ meter dipped into the sample. The meter was switched on and allowed to stand for 30 minutes while the $\mathrm{pH}$ value was recorded.

3) Chloride: The apparatus were the weighing balance, syringes, plastic vessel, and small plastic containers. The chloride level in $\mathrm{mg} / \mathrm{l}$ (ppm) was determined by mercuric nitrate titration. Two drops of diphenylcarbazone indicator were added and mixed carefully by swirling the vessel in circles. Nitric acid was added drop wise until the solution turns yellow. The titration syringe's tip was inserted into mercuric (nitrite solution) solution and the plunger pulled out until the lower edge of the plunger seal is on the $0 \mathrm{ml}$ mark of the syringe. The titration solution was slowly added drop wise and swirled until the colour changed from yellow to violet. The millilitres of titration solution from the syringe scale was read off and multiplied by 1000 to obtain $\mathrm{mg} / \mathrm{l}$ (ppm) chloride.

4) Hardness: The apparatus used were titer syringe plastic vessel, small transparent plastic container and buffer solution. The cap from the small plastic syringe was removed and rinsed with the sample water. The sample was filled to $0.5 \mathrm{ml}$ mark and the cap replaced. Five drops of hardness buffer solution were added and mixed carefully. One drop of calmagite indicator was then added. Take the titration syringe and push the plunger completely into the syringe. Tip of the syringe was inserted into ETDA solution and pulled out until its lower edge is on the $10 \mathrm{ml}$ mark of the syringe. The EDTA titration solution is slowly added drop wise and swung to mix after each drop until the colour changes.
The milliliters of titration solution were read off from the syringe scale and multiplied by 300 .

5) Alkalinity: Apparatus included transparent plastic vessel, calibrated syringe, bromophenol blue indicator, and titrant solution. The cap is removed from the plastic vessel rinsed with the sample and filled with the sample to $0.5 \mathrm{ml}$ mark. The cap is replaced. Drops of Bromophenol blue indicator were added and the titration syringe filled to $10 \mathrm{ml}$ with H13811.0 solution. Titration solution is added drop wise, mixed after each drop until a colour change is noted. The milliliters of titration solution used were read off from the syringe scale and multiplied by 300 to obtain $\mathrm{mg} / \mathrm{l}$ (ppm).

6) Conductivity: Digital conductivity meter was used. The conductivity was determined by dipping the electrode into the water sample directly in a beaker and allowed to stand for 30 minutes before taking the reading.

7) Colour: $10 \mathrm{ml}$ of each sample was measured in the glass bottle given. Bottle was placed in the colour test machine. Read direct was pressed on the machine. Colour reading was shown on the LCD screen of the machine.

8) Nitrate: A $15 \mathrm{ml}$ of water was prepared into two glasses each containing $5 \mathrm{ml}$ of water sample. One of the glasses was placed into left hand opening of the checker disk. This was noted as the blank. A pocket of reagent was added to the other sample and properly mixed. The solution was marked as reacted sample and was placed at the right hand opening of the checker disk at a distance of about 30 to $40 \mathrm{~cm}$ away, and across a light source to illuminate the sample to be matched. The disk was rotated while looking at the sample through the colour test window until the colour is matched. The value in the test window is read as $\mathrm{mg} / \mathrm{l}$ of nitrate or nitrogen $\left(\mathrm{N}-\mathrm{NO}_{3}\right)$.

9) Turbidity: 10 NTU (Nephelometric Turbidity Units) with 1 - 10 NTU graduated standard was used. A portion of water sample was poured into a clear and clean test tube was shaken thoroughly and later inserted into the sample chamber of standardized turbid meter (1 - 10 NTU graduated). The value was read off directly from the scale. This procedure was also repeated for other samples.

10) Iron: Apparatus used were colour comparator cube and plastic vessels. The cap was removed from the plastic vessel and rinsed with water sample. It was then filled to the $10 \mathrm{ml}$ mark. 1 packet of the iron reagent HI 3834-0 was added. The cap was replaced and the solution mixed until solids dissolved. The cap was removed and the solution transferred into the colour comparator cube. The colour that matches the solution in the cube was recorded as $\mathrm{mg} / \mathrm{l}(\mathrm{ppm})$ iron.

11) Magnesium: Demineralizer bottle, plastic vessel, filter paper disc, funnel, pipette were the apparatus used. The cap was removed and the Demineraliser bottle filled 
with tap water. The cap was replaced and the bottle shaken for at least 2 minutes to prepare the demineralised water. One of the large (50 mg/l) plastic vessels was filled with $25 \mathrm{ml}$ of water sample, up to the mark. Four (4) drops of Buffer Reagent were added and swirled to mix. One (1) packet of HI 38079A-0 Oxalate reagent was added and stirred for 30 seconds by means of the plastic spoon. This was left for about 5 minutes for the reaction to complete. A folded filter paper into cone was placed in the funnel and the funnel placed over the other larger plastic vessel. The reacted water sample was poured through the filter paper. Using the $3 \mathrm{ml}$ plastic pipette, 3 $\mathrm{ml}$ of the filtered clear water sample was carefully transferred into the small $(20 \mathrm{ml})$ plastic vessel. The top of the Demineraliser bottle cap was flipped open. By gently squeezing the bottle, the demineralised water was added to the vessel up to the $10 \mathrm{ml}$ mark. Using the $1 \mathrm{~mL}$ plastic pipette, $1 \mathrm{~mL}$ of Buffer Solution was added and swirled to mix. One (1) drop of Calmagite indicator was added and swirled to mix. The syringe's plunger was pushed completely into the HI 380798-0 EDTA solution bottle and pulled out until the lower edge of the seal is on the $0.0 \mathrm{ml}$ mark of the syringe. Titration solution was slowly added drop by drop, swirling after each drop. As the colour changes from pink to purple, it was swirled for 15 seconds after each additional drop, until the solution turns pure blue. The millilitre of titration solution was read off from the syringe.

Calculation of the $\mathrm{mg} / \mathrm{l}(\mathrm{ppm})$ of Magnesium in the sample was as follows: ppm of $\mathrm{mg}=\mathrm{ml}$ of titrant $\times 243$.

12) Sulfate: Apparatus: plastic vessel, spoon, plastic pipette, test tube. The plastic vessel was filled with $50 \mathrm{ml}$ of the sample up to the mark. One (1) packet of $\mathrm{HI}$ 38000A-0 Sulfate Reagent was added and swirled gently to dissolve. Two (2) drops of Complexing Agent was added and swirled to mix. Two (2) spoons of HI 38000B0 reagent were added and swirled gently to mix. This was left for 5 minutes to allow reaction to occur. The test tube was kept on a white surface and viewed from the top at the black spot on the bottom. The plastic pipette was used to fill the tube with the reacted sample until the black spot has completely disappeared. The concentration in $\mathrm{mg} / \mathrm{l}$ (ppm) of sulfate was read in correspondence of the level of the liquid in the test tube.

13) Biological Oxygen Demand (BOD): The apparatus used include: incubator bottles of 125, 250 or $300 \mathrm{ml}$ capacity with ground glass stopped; air-cooled insulator (this is thermostatically controlled at $20^{\circ} \mathrm{C}$ ); high quality distilled or deionized water; phosphate buffer solution; magnesium sulphate solution; calcium chloride solution; and iron (III) chloride solution. Preparation of dilution water was by storing the distilled water in a large incubator bottle whose mouth is plugged with clean cotton wool as to permit it to be saturated with sufficient Dis- solved Oxygen. To the distilled water was added $1 \mathrm{ml}$ of each of the following reagents: phosphate buffer magnesium sulphate, calcium chloride and iron (III) chloride solution. The water sample was pre-heated with $0.5 \mathrm{~m}$ acid or $1 \mathrm{M}$ alkali if necessary to about $\mathrm{pH} 7$ if it contains chloride compounds, to chlorinate with adequate quantity of $0.125 \mathrm{M} \mathrm{Na}_{2} \mathrm{SO}_{3}$. Several solutions of the prepared sample were made so as to obtain adequate drop in oxygen content. The following dilutions were found adequate: $1 \%$ - $2 \%$ for raw wastewater; $2 \%$ - 3\% for settled wastewater; $5 \%$ - 30\% for biological treated wastewater; $3 \%$ - 7\% for chemically treated wastewater; 35\% - 100\% for river water. Suitable amounts of sample were measured into BOD bottles in duplicates by the aid of large tip volumetric pipette. Bottles were filled to the brim with dilution water in accordance with the percentage of dilution required. The stoppers were inserted without leaving air bubbles. Dilution greater than $1 \%$ was made by diluting the water in a volumetric flask before transferring it, carefully into BOD for final dilution. Since the sets of dilutions are made in duplicate, the initial DO was determined on the one set for 5 days in the dark at $20^{\circ} \mathrm{C}$ in a cooled incubator. Thereafter, the DO in the incubated samples and the blank was determined.

The BOD was then calculated.

14) Coliform Bacteria Determination: Apparatus used was Petri Dish Incubator. A $50 \mathrm{mg}$ of MacConkey agar was weighed and 1 litre of deionized water added. This was allowed to soak for 10 mins, swirled to mix and sterilized by autoclaving at $121^{\circ} \mathrm{C}$ for 15 mins. The mixture was cooled to $47^{\circ} \mathrm{C}$ and poured into petri dish. A dry surface was ensured before inoculation by partial exposure at $37^{\circ} \mathrm{C}$. A $0.5 \mathrm{ml}$ portion of the sample was taken and poured into the petri dish, the prepared MacConkey agar solution was added and the dish covered. This was placed in the incubator for $24 \mathrm{hrs}$ at $30^{\circ} \mathrm{C}$. This was later removed and placed on the colony counter for determination of the number of coliform bacteria formed.

\section{Results and Discussion}

\subsection{Questionnaires}

1) Water supply: The questionnaires revealed that the major source of water supply in the area is from well which is most available throughout. Figure 1 illustrates the water supply pattern in the study area. It was also found out that the mode of collection of water from the source is majorly by head porterage with few uses of vehicle due to the distance of water source. Furthermore the respondent also testifies that water is always stored inside the tank for later use and that they do not pay for the water since the wells are many and most of them are privately owned.

It is clearly shown from Figure $\mathbf{1}$ that even though the 
Water supply pattern in the study area

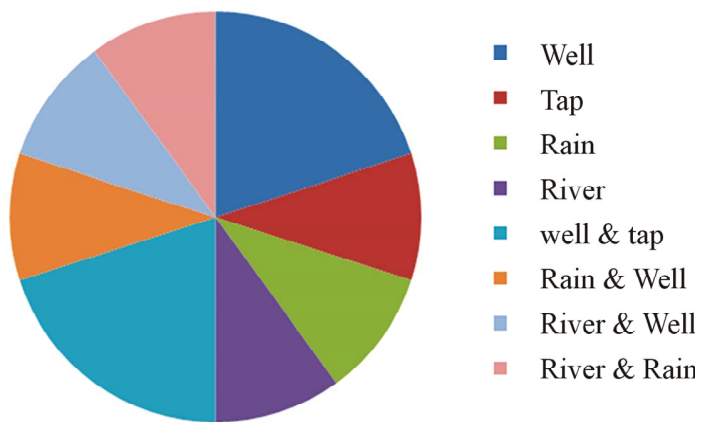

Figure 1. Water supply pattern in the study area.

majority of the respondents depend on both well and tap water, well water remains the source of water with highest sole patronage.

2) Water quality: The survey revealed that most residents used water directly from the source without much treatment except a few who boil theirs. It was also found that refuse dumps are located on some uncompleted buildings within the range of $100 \mathrm{~m}$ or more to a few of the water sources. The respondents confirmed that there is likelihood of the contamination of their water by leachates emanating from these waste dumps. Again, according to the respondents there is no certification of good water quality by any authority. The respondents allude the ailments and water borne diseases which had affected the area in the past to this uncertified water quality.

Figures 2 to 9 illustrate patterns of other components of the questionnaire like the water use prior to or after treatments; types of contaminants; method of water treatment; water quality control; occurrence of water-borne diseases; proximity of refuse dump to the water source; incidences of water-borne disease outbreak in the area; effects of water-borne diseases and the availability of stagnant water in the surrounding. The numbers 1 to 10 in horizontal axes of the graphs in Figures 2 to 9 represents the 10 selected locations in this order; Ajegunle, Arinkinkin, Arowomole, Caretaker, Esanu-Aje, Ita-Olola, Malete, Oke-Alapata, Ora-Gada and Sunsun.

It could be observed from Figure $\mathbf{2}$ that more residents use their water directly without subjecting it to treatments as common in most rural areas of developing countries. Forty (40) is the maximum percentage of those treating their water before usage. This may be responsible for the high incidents of water-related diseases noted in the area.

Figure 3 shows that most residents believed have human or animal wastes dominating the contamination of their water sources and this was closely followed by municipal wastes which perhaps generate leachate contaminants. Since the level of industrial activities in the area is very low, it could account for the view that there is low industrial contamination.

The results of responses on method of water treatment revealed that simple boiling was adopted by about $60 \%$ $70 \%$ of those treating their water before consumption in most locations. Residents of Esanu-Aje and Caretaker however adopt chemical treatment method of adding aluminium sulphate (alum) more than others using same treatment method. Treatments by UV light, Ozonation, Poly-electrolytes are not common in the area.

As revealed in Figure 5, majority do not subject their water to any quality control or certification before its use. Physical screening is being used in only 5 locations whereas nearly $50 \%$ of the respondents assumed that their pipe-borne/tap water is already treated by the government. It is only in Ajegunle area that few residents claim to subject their water to laboratory analysis, probably due

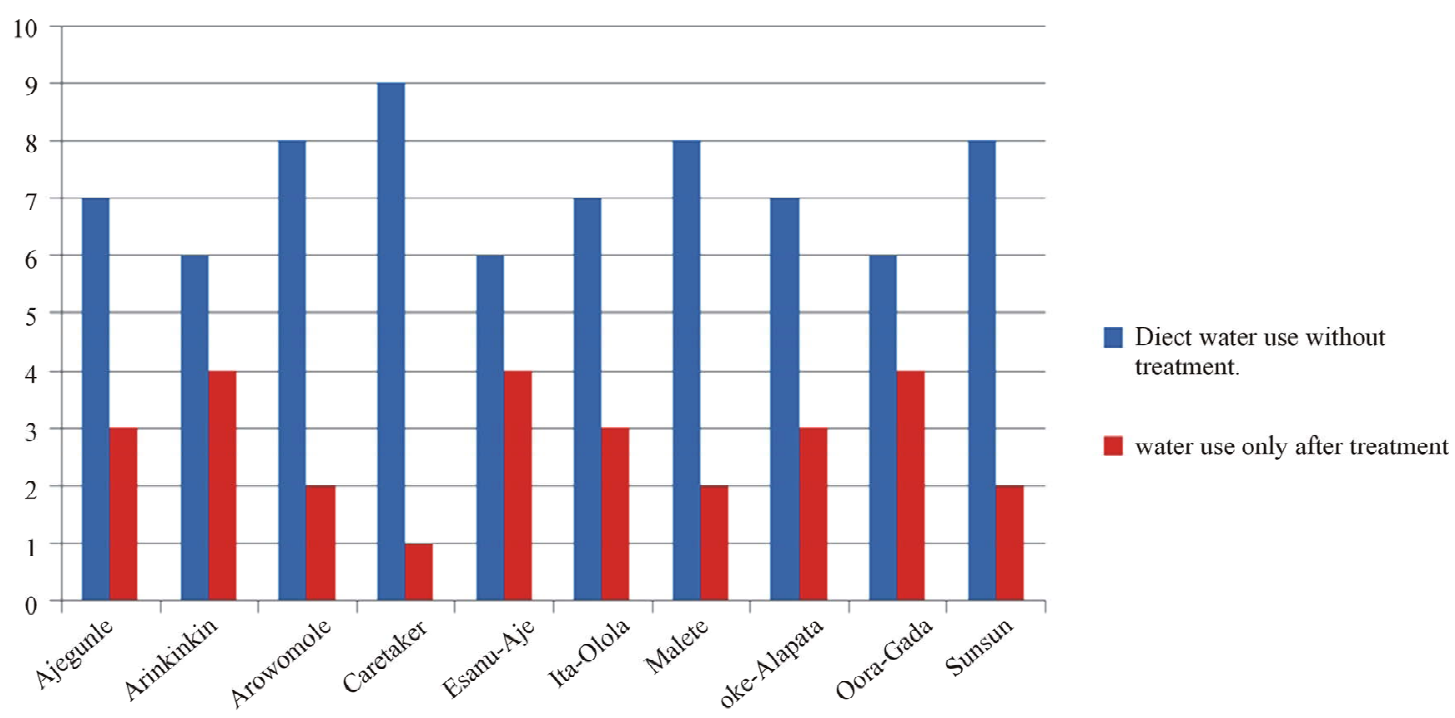

Figure 2. Water use prior to or after treatments. 


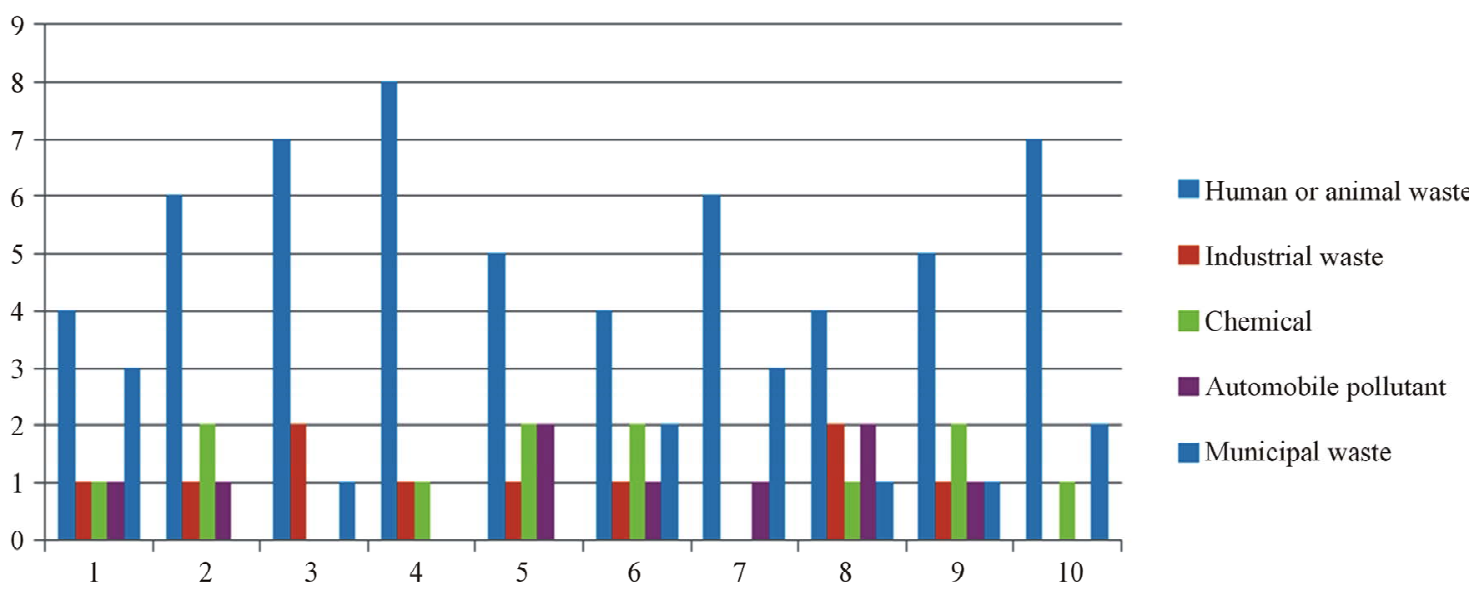

Figure 3. Types of Contaminants.

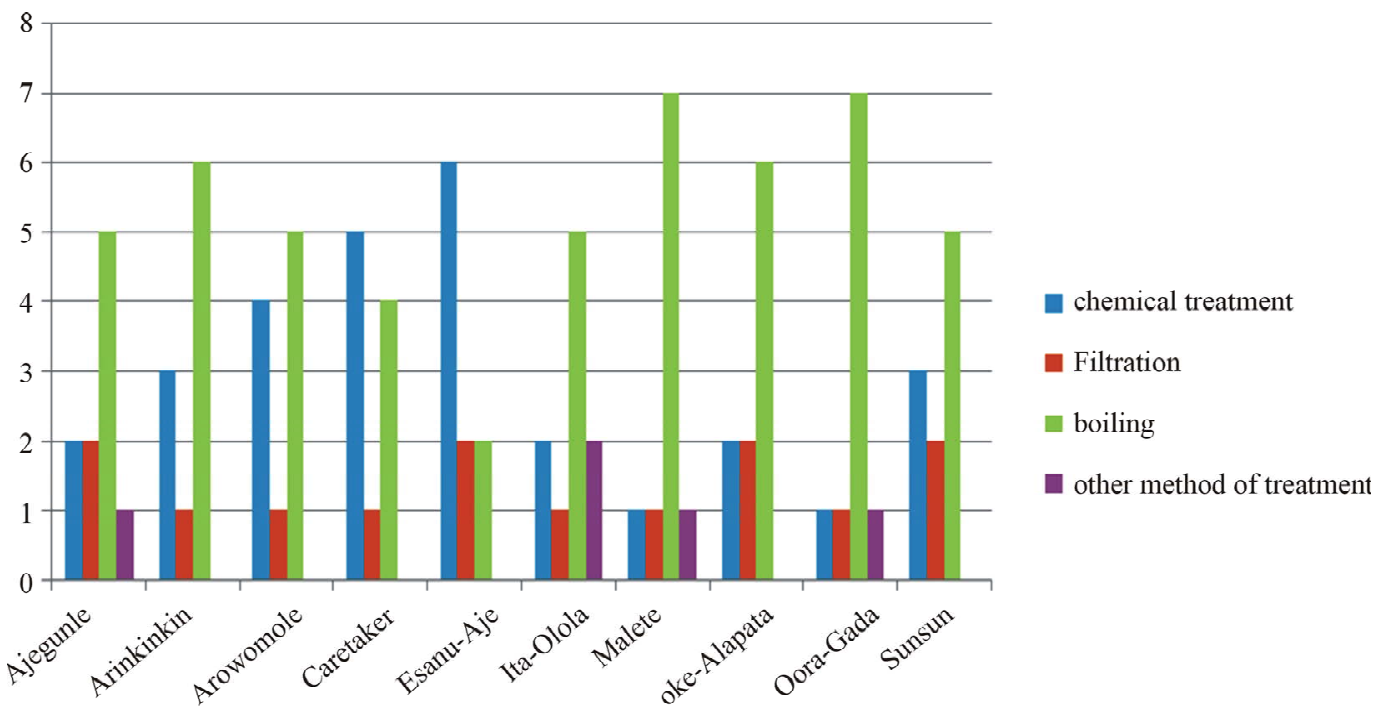

Figure 4. Method of water treatment.

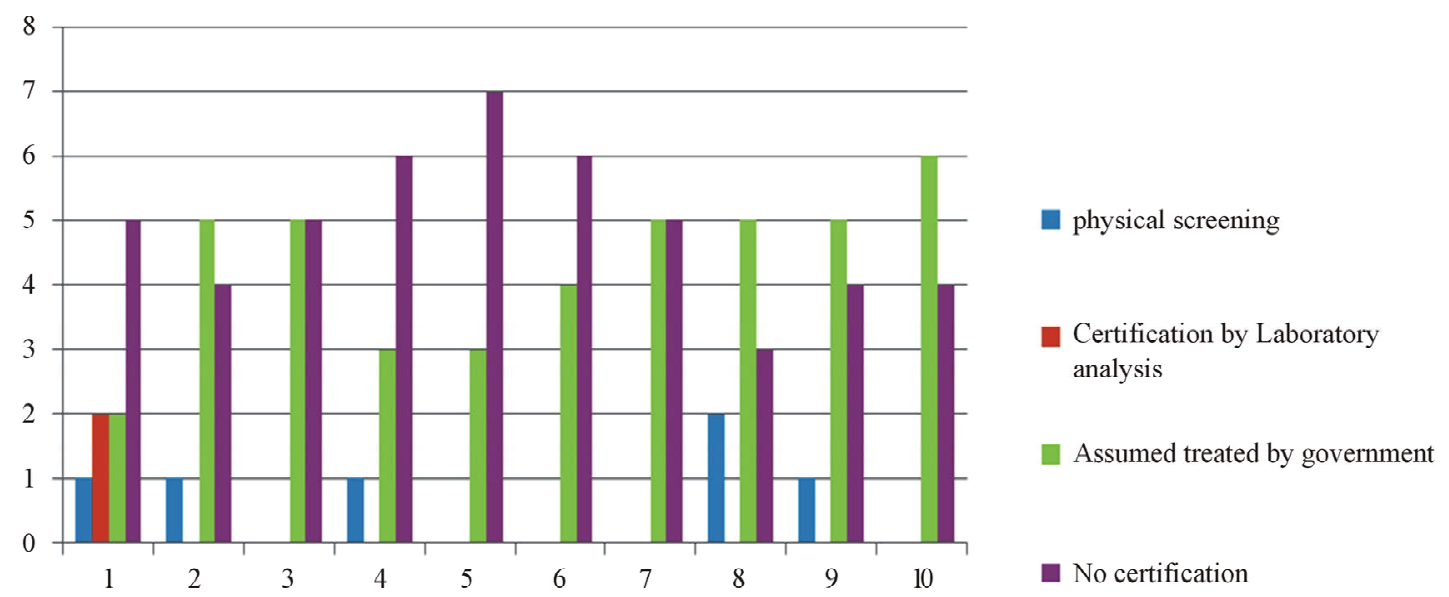

Figure 5. Water quality control.

to their proximity to the waterworks.

All locations except one had the refuse dumps farther than $100 \mathrm{~m}$ from the water source. Equal numbers of residents have their dumps both far away from and near the water source in Malete area.

From the result of the questionnaire survey presented 
in Figure $\mathbf{7}$ indicates that residents in all the areas had at one time or the other experienced water-borne diseases. Those yet to experience it are however on the higher figures, especially at Sunsun and Ajegunle areas. Even though this had not been a regular occurrence according to the respondents, yet at different times residents have fallen victims of the health challenges caused by contaminated water. This is in agreement with an earlier research finding that contaminated water accounts for most of the diseases in the tropics [13]. As a rider to these incidences, Figure 8 displays the respondents' awareness levels of the effects. Except at Ajegunle and Arinkinkin where equal numbers of residents were both affected and otherwise, in the rest locations more respondents had been affected by the water-related diseases in the previous times.

Most respondents at Arinkinkin, Malete and Ajegunle areas claimed to notice stagnant waters in their sur

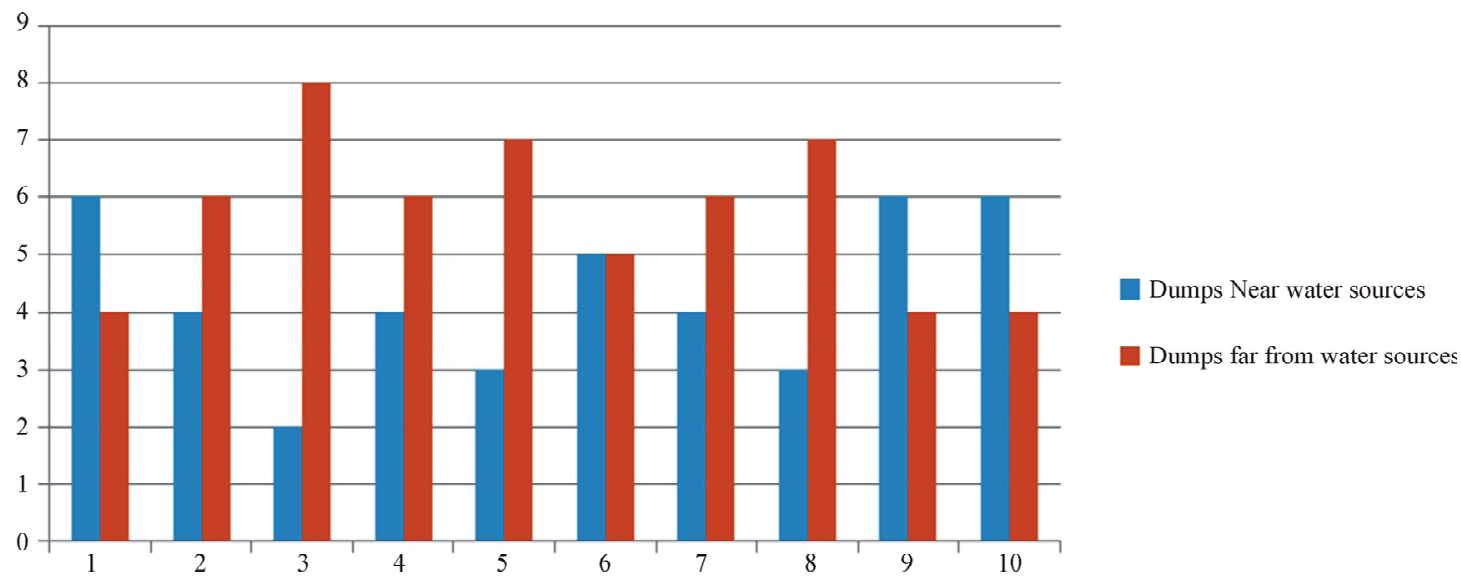

Figure 6. Proximity of refuse dump to the water source.

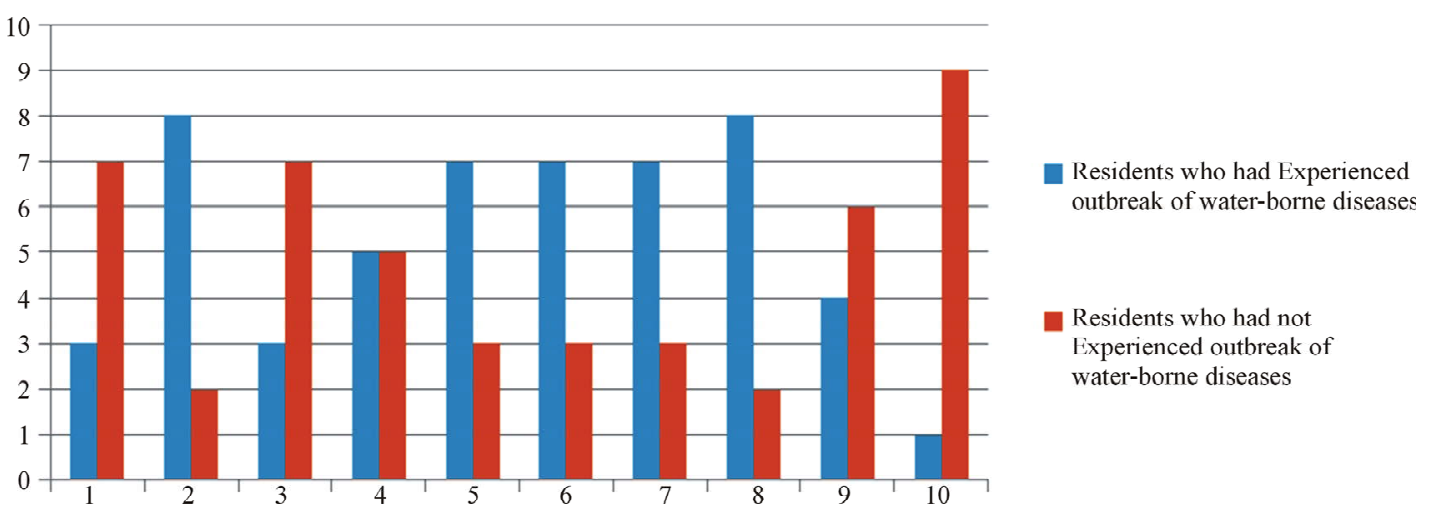

Figure 7. Incidences of water-borne disease outbreak in the area.

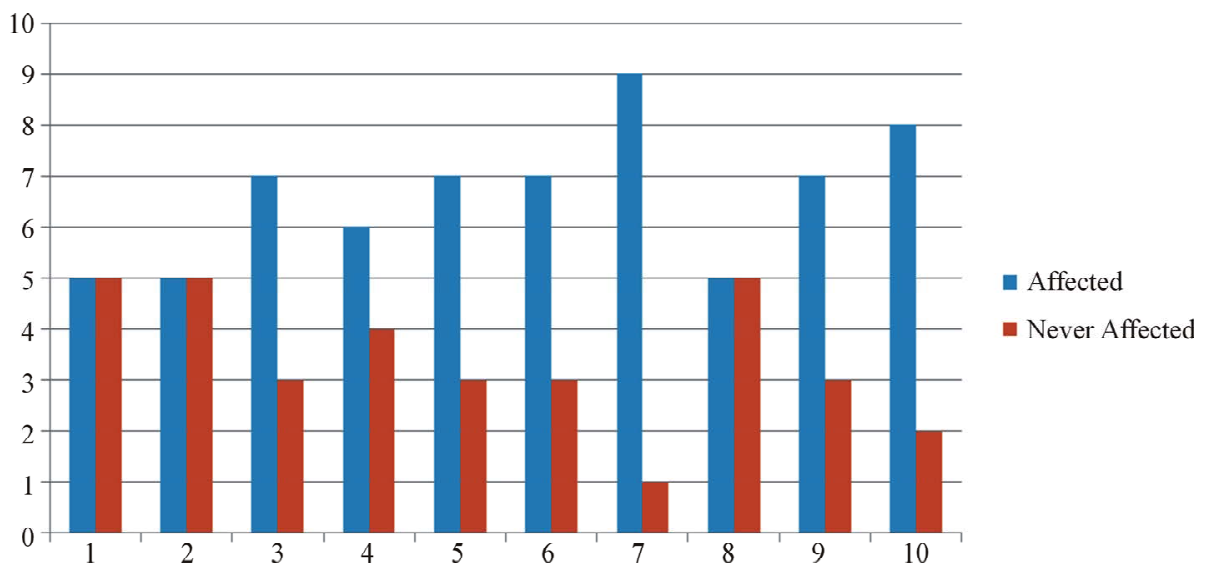

Figure 8. Effects of water-borne diseases. 
roundings (Figure 9). This could be spring boards for mosquitoes and other vectors capable of affecting human health negatively. In six (6) other locations surveyed, equal numbers of respondents have and do not have stagnant waters within their neighbourhoods.

\subsection{Results of the Laboratory Analysis on Water Samples from Selected Wells}

The results of the Laboratory analysis conducted on selected wells in Ogbomoso South Local Government were presented in Tables 1 and 2. The graphical representations are in Figures 10 to 12. These were compared with the guidelines on drinking water by National Primary Drinking Water Regulations (NPDWRs, US), World
Health Organization (WHO) and National Agency for Food and Drug Administration and Control (NAFDAC) on Table 3. The basis of comparison is to determine its potability of the water for intended use.

1) Appearance-All the ten samples gotten from the study area were observed to be clear.

2) Colour-Sample taken from Ajegunle and EsanuAje area were observed to have the colour value of 40 TCU and 70 TCU respectively, where other area has no observable colour. With reference to Figure 10, the standard was represented by a straight line graphs i.e. 15 TCU according to the specification given by National Primary Drinking Water Regulations, U.S (NPDWRs). It is clearly shown that the sample taken from Ajegunle and

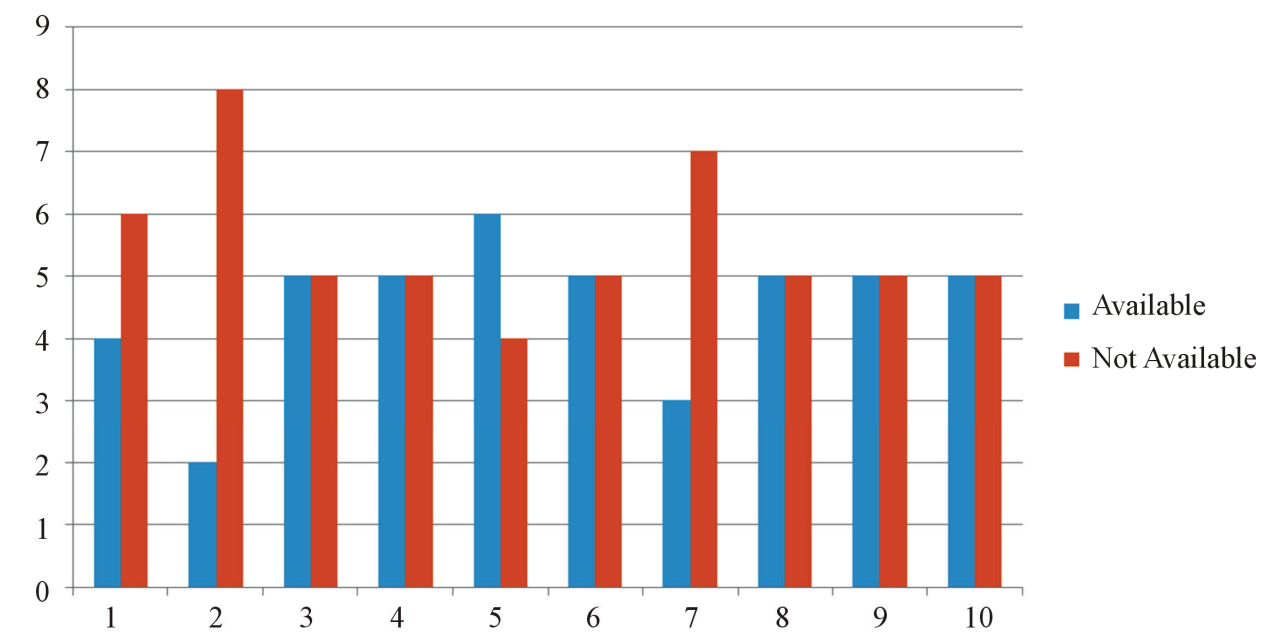

Figure 9. Availability of stagnant water in the surrounding.

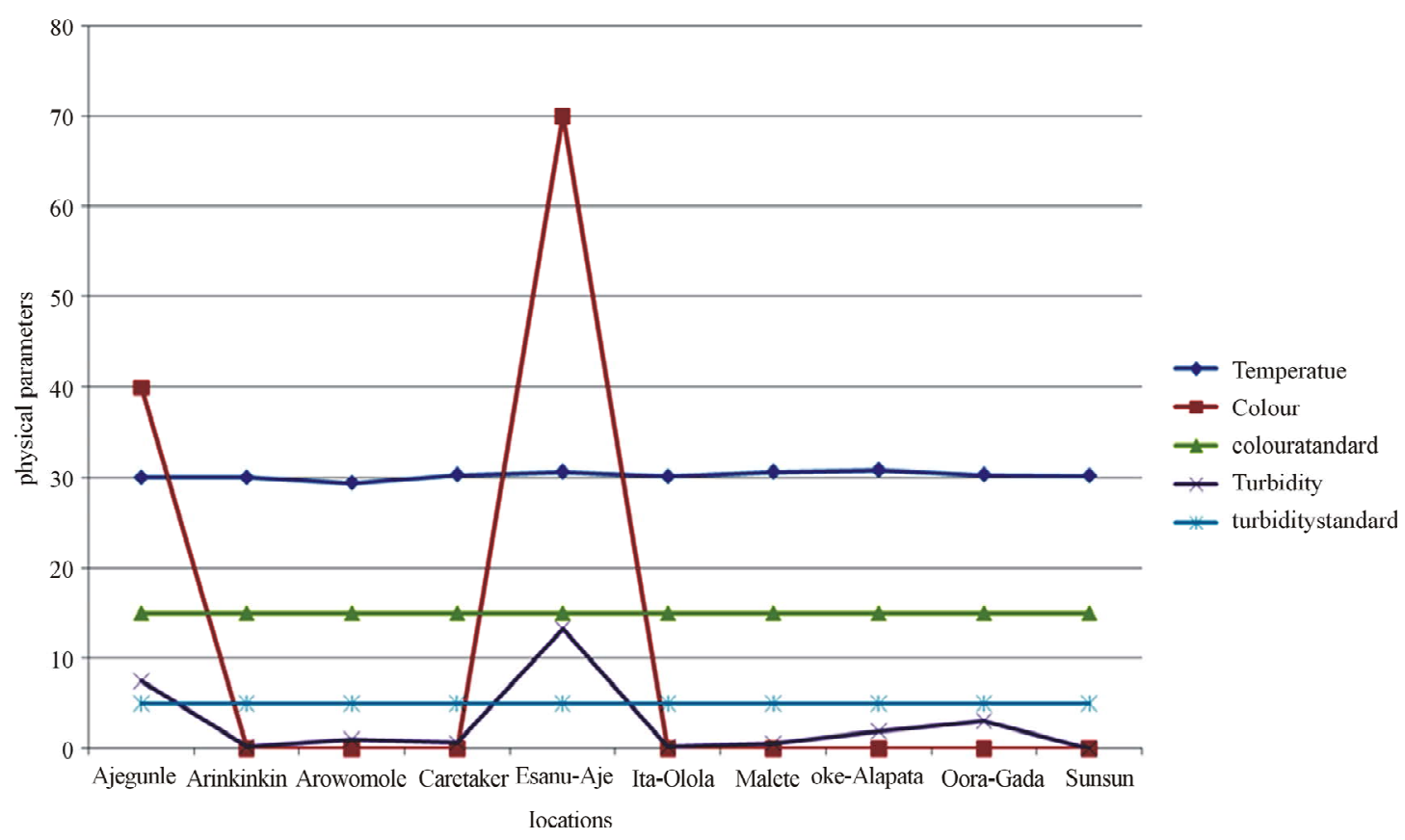

Figure 10. Physical parameters and locations. 


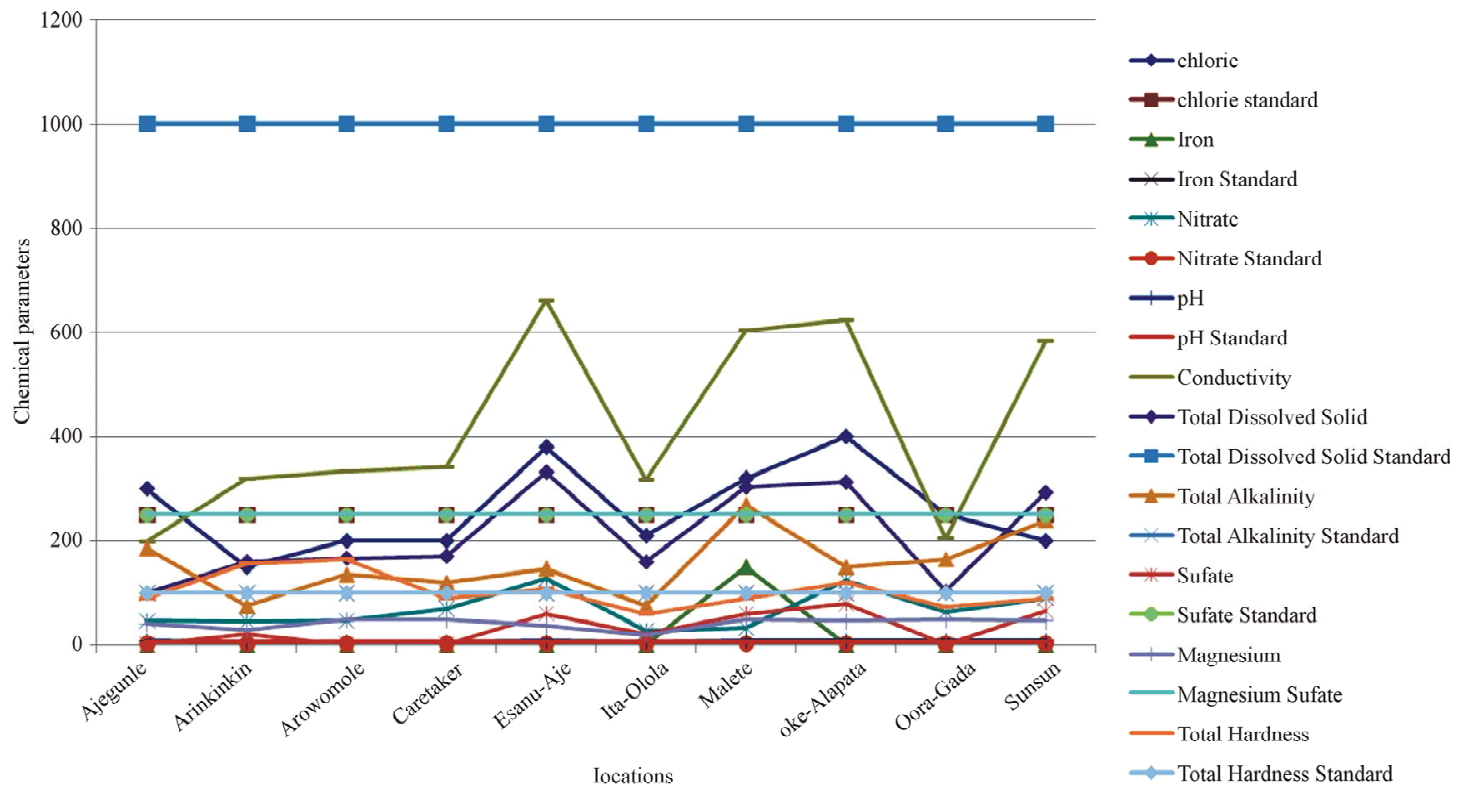

Figure 11. The distribution of chemical parameters in the studied wells.

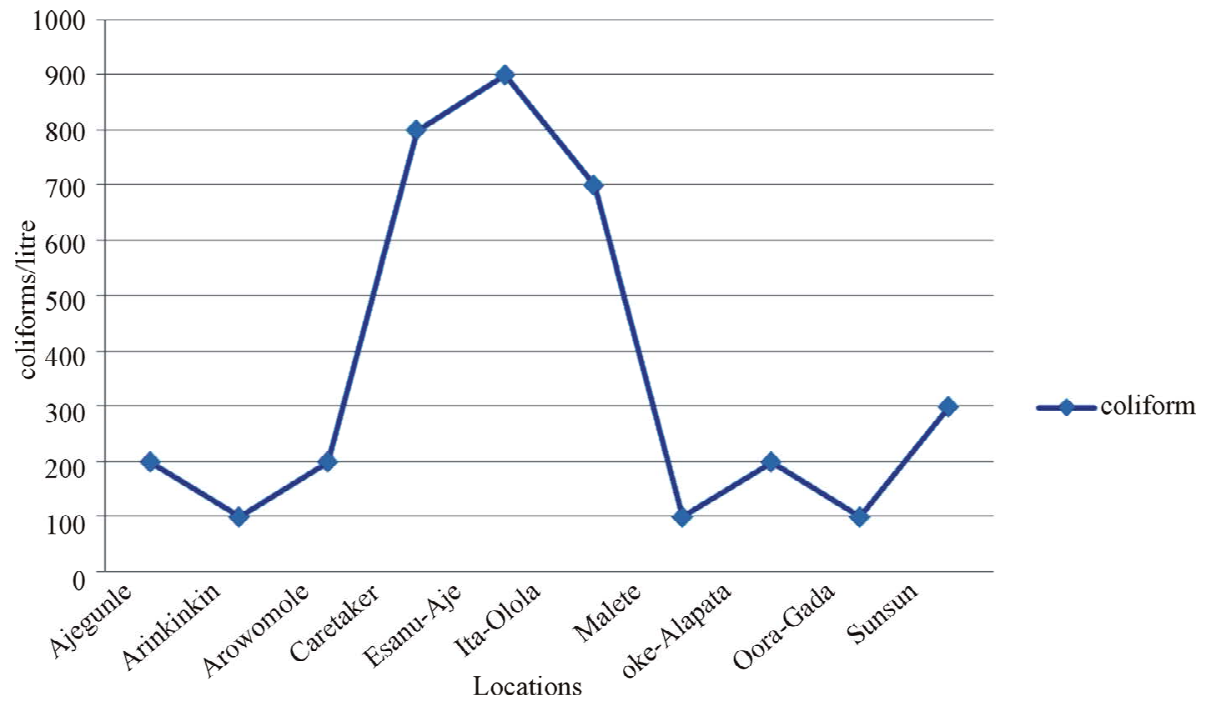

Figure 12. Graph of the Coliform levels in the study area.

Esanu-Aje areas have colour values above the standard as it is shown in Figure 10. Meanwhile other locations (i.e. Arinkinkin, Arowomole, Caretaker, Ita-olola, Malete, Oke Alapata, Oora-Gada and Sunsun) have zero colour value as clearly shown on the graph in the same Figure.

3) Odour-No odour was noticed from the entire sample before and after the collection. Thus they have unobjectionable odour which meet the standard of both WHO and NAFDAC as case may be.

4) Turbidity-There was no wide variation in the measured value of the turbidity obtained, as the value ranges from $0.00 \mathrm{NTU}-13.25 \mathrm{NTU}$. It is clearly shown from the analysis that sample taken from Esanu-Aje area of Ogbomoso south Local Government is highly turbid. This value is above the recommended limit by WHO, NAFDAC and NPDWRs which is 5 NTU, while the sample from Sunsun is the least turbid. Ajegunle and Esanu-Aje areas have turbidity value above the standard, as indicated in Table 4. Sample taken from Ajegunle area has 7.50 NTU while Sample from Esanu-Aje has 13.25 NTU, while other locations fell below the WHO, NAFDAC and NPDWRs standard. By way of comparing turbidity with the colour it is observed that Location with high turbidity value has the highest colour value and vice-versa.

5) Temperature-Temperature is usually attributed to weather condition, season, and time of days. The samples 
Table 1. Results of laboratory tests for the samples.

\begin{tabular}{|c|c|c|c|c|c|c|c|c|c|c|}
\hline Parameters & Ajegunle & Arinkinkin & Arowomole & Caretaker & Ita-Olola & Malete & Oke-Alapata & Oora-Gada & Esanu-Aje & Sunsun \\
\hline Chloride (mg/l) & 300 & 150 & 200 & 200 & 210 & 320 & 400 & 250 & 380 & 200 \\
\hline Hardness (mg/l) & 90 & 156 & 165 & 90 & 60 & 90 & 120 & 75 & 108 & 90 \\
\hline Iron (mg/l) & 0 & 0 & 0 & 0 & 0 & 0 & 150 & 0 & 0 & 0 \\
\hline Colour (TCU) & 40 & 0 & 0 & 0 & 0 & 0 & 0 & 0 & 70 & 0 \\
\hline Turbidity (NTU) & 7.50 & 0.28 & 1.03 & 0.66 & 0.27 & 0.60 & 1.97 & 3.10 & 13.25 & 0.00 \\
\hline $\mathrm{pH}$ & 7.24 & 5.99 & 6.40 & 6.33 & 5.99 & 7.26 & 8.12 & 7.99 & 8.21 & 7.46 \\
\hline Nitrate (mg/l) & 46.07 & 45.19 & 46.07 & 69.55 & 26.54 & 32.16 & 123.59 & 62.46 & 127.58 & 89.93 \\
\hline Conductivity(mg/l) & 198 & 320 & 333 & 341 & 318 & 605 & 625 & 205 & 663 & 585 \\
\hline $\begin{array}{l}\text { Total dissolve solid } \\
\text { (mg/l) }\end{array}$ & 99 & 160 & 166.5 & 170.5 & 159 & 302.5 & 312.5 & 102.5 & 331.5 & 292.5 \\
\hline Alkalinity (mg/l) & 186 & 75 & 135 & 120 & 75 & 270 & 150 & 165 & 147 & 240 \\
\hline Sulfate (mg/l) & below 20 & 20 & below 20 & below 20 & 21 & 60 & 80 & below 20 & 60 & 65 \\
\hline Magnesium (mg/l) & 41.31 & 29.16 & 48.6 & 48.5 & 19.44 & 48.6 & 46.17 & 48.6 & 36.45 & 46.17 \\
\hline Temperature $\left({ }^{\circ} \mathrm{C}\right)$ & 30 & 30 & 29.4 & 30.3 & 30.1 & 30.6 & 30.8 & 30.3 & 30.6 & 30.2 \\
\hline $\begin{array}{l}\text { Dissolve Oxygen } \\
\text { (mg/l) }\end{array}$ & 4.3 & 3.0 & 4.5 & 5.0 & 3.2 & 3.91 & 5.09 & 4.02 & 3.50 & 3.71 \\
\hline BOD 5(mg/l) & 4.19 & 4.28 & 4.31 & 4.27 & 4.09 & 4.21 & 4.19 & 4.27 & 4.09 & 4.18 \\
\hline Coliform $/ \mathrm{ml}$ & 200 & 100 & 200 & 800 & 700 & 100 & 200 & 100 & 900 & 300 \\
\hline Appearance & cloudy & clear & clear & clear & clear & clear & clear & clear & cloudy & clear \\
\hline Odour & & & & & & & Unobjectionable & & & \\
\hline
\end{tabular}

from the study area have a maximum temperature of $31^{\circ} \mathrm{C}$.

6) $\mathbf{p H}$-The $\mathrm{pH}$ of well water, the samples varied from slightly acidic to slightly alkaline with the $\mathrm{pH}$ range of 6.0 to 8.21. The $\mathrm{pH}$ was found highest in Esanu-Aje (8.21) and Oke-Alapata (8.12) and Lowest in Arinkinkin (6.0), Ita-Olola (6.0) and Caretaker (6.33). Generally, the water is found to be slightly acidic in most area and alkaline in some parts as no health implications were attached. From Table 3 the $\mathrm{pH}$ values fell within the maximum acceptable concentration.

7) Total dissolved solids-The total dissolved solid in these areas vary over a range of 99 - $332 \mathrm{mg} / \mathrm{l}$. The highest value occurs at Esanu-Aje (332 mg/l), Oke-Alapata (313 mg/l) and Malete $(303 \mathrm{mg} / \mathrm{l})$ and lowest occur at Ajegunle (99 mg/l), the Total Dissolved Solids of all the samples are within the maximum accepted concentration when compared with the standard given by the W.H.O as indicated in Table 3. Any slight increase above the standard given by the W.H.O is an indication that some individual living in the area is prompt to gastrointestinal irritation. The conductivity from Esanu-Aje is also very high (663 mg/l) and very low at Ajegunle (198 mg/l).

8) Total Alkalinity—varies from a minimum of 75 $\mathrm{mg} / \mathrm{l}$ at Arinkinkin and Ita-Olola which could be as a result of contamination by carbonate salt. From Figure $\mathbf{1 1}$ it is clearly shown that Arinkinkin and Ita-Olola have the values that fell within the standard while others have the value above the standard given by NAFDAC.

9) Chloride-The chloride content of the well in the study area fells within the range of $150-400 \mathrm{mg} / \mathrm{l}$ which indicates that some areas exceed the WHO (1993) recommended limits $(250 \mathrm{mg} / \mathrm{l})$. The highest value occurs at Oke-Alapata $(400 \mathrm{mg} / \mathrm{l})$ and lowest value occurs at Arinkinkin (150 mg/l) as indicated in Table 1, this could be as a result of laundry activities taking place near the area. Excess of the chlorine in water sample results in cancer diseases.

10) Nitrate-The value of the nitrate content ranges from $26.54-127.58 \mathrm{mg} / \mathrm{l}$. The highest value occurs at Esanu-Aje $(127.58 \mathrm{mg} / \mathrm{l})$ and the lowest value occurs at Ita-Olola $(26.54 \mathrm{mg} / \mathrm{l})$ as clearly shown in Figure 11. When compared with the standard, this range exceeds the maximum acceptable concentration given by W.H.O, this is an indication that the samples contain nitrate in excess which can cause shortness of breath and blue-baby syndrome in infants below the age of six months who drink water containing nitrate in excess. 


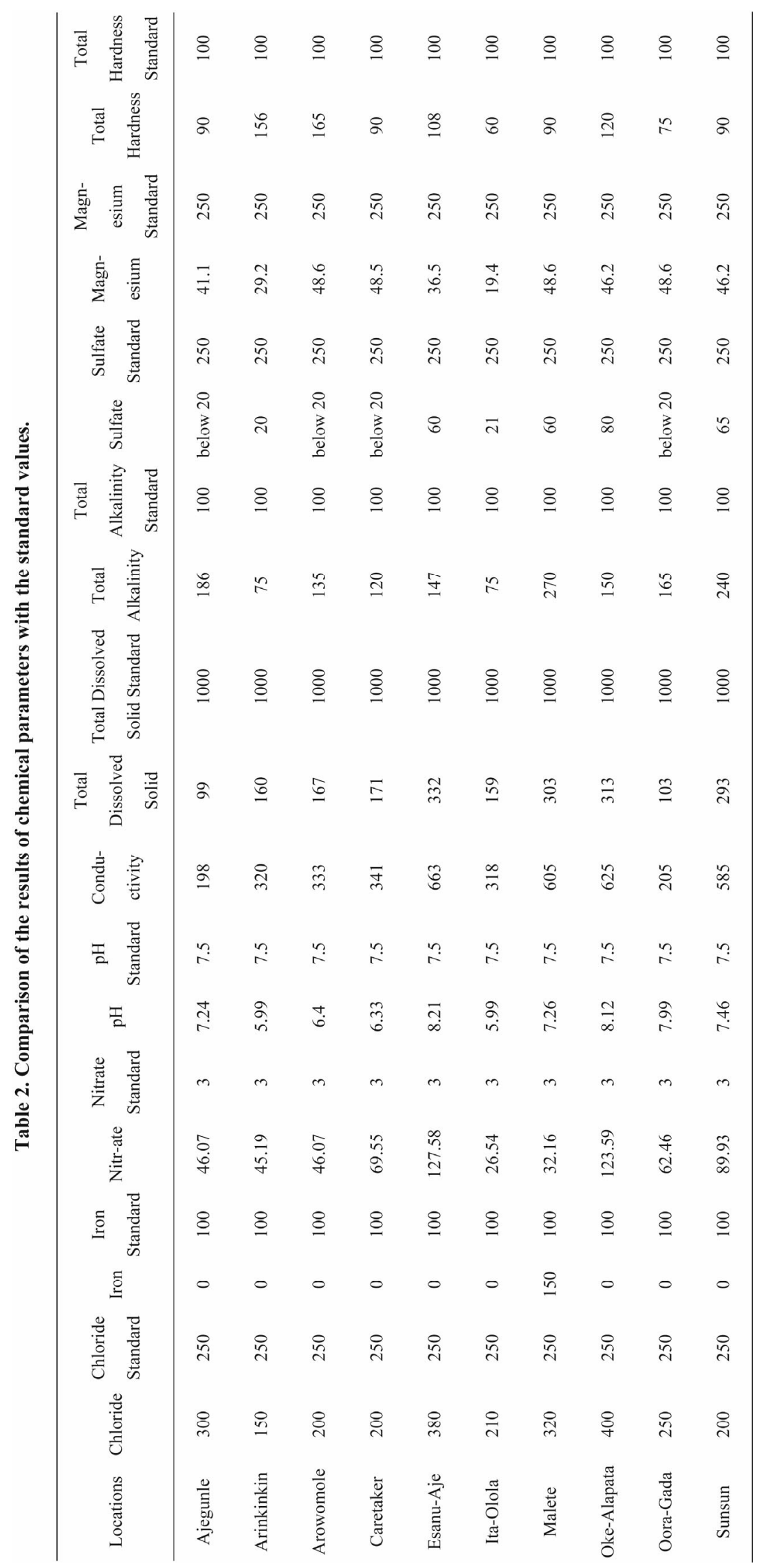


Table 3. World health organization (WHO), national agency for food and drugs administration control (nafdac) and npdwrs standards for drinking water.

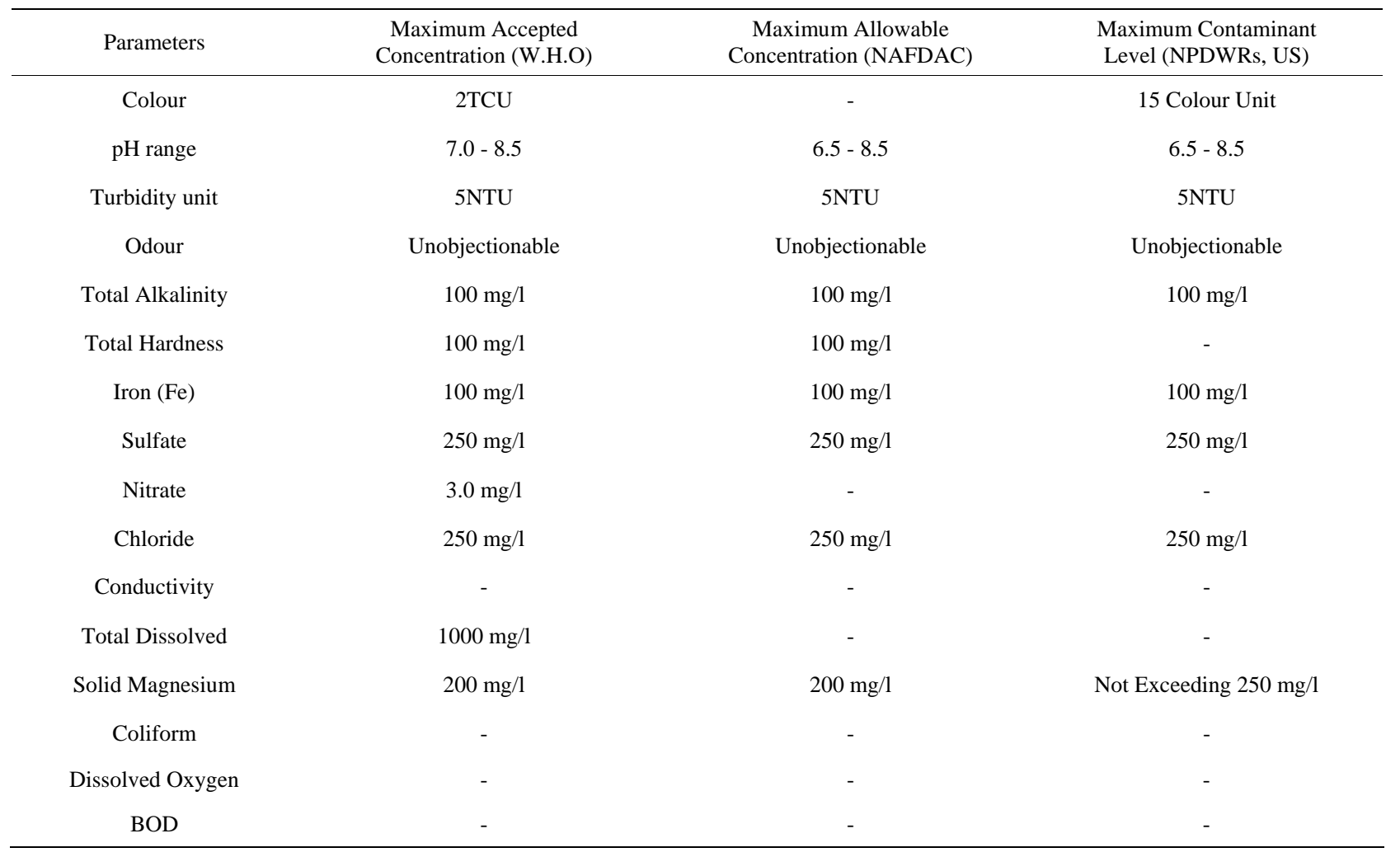

Source: NAFDAC (2001), Consumer Safety Bulleting.

11) Sulfate-The sulfate content of the well in the study area ranges from below 20 - $80 \mathrm{ppm}$. The sample taken from Oke-Alapata has the highest sulfate content as $80 \mathrm{ppm}$ while Ajegunle, Arinkinkin, Arowomole and Oora-Gada have the lowest sulfate content and this is indicated by graph in Figure 11. When compared with the standard the range falls within the maximum acceptable concentration. Potential health effects from the injection of water with excess sulfate content are; gastrointestinal irritation (loose stools, diarrhoea, etc) especially in infants or individuals not acclimated to high level.

12) Iron-The iron value ranges from $0.00-150 \mathrm{mg} / \mathrm{l}$. There is no Iron detection in Ajegunle, Arinkinkin, Arowomole, Caretaker, Esanu-Aje, Ita-Olola, Oora-Gada, Oke-Alapata, and Sunsun except sample taken from Malete area that was polluted with Fe. The value of the Iron in Malete exceeds WHO recommended value (100 $\mathrm{mg} / \mathrm{l}$ ) as shown clearly in Table 1 and Figure 11. Possible Implications of presence of Iron are the staining of laundry, plumbing, appliances which will impact contaminants into the water.

13) B.O.D-According to drinking water standards as given by W.H.O, NAFDAC and NPDWRs, Biochemical Oxygen Demand (BOD) and E. coli should be completely absent in a sample of water in order to be safe for drinking and other intended use. From the bacteriological tests carried out, shows that samples collected from the wells have bacterial contaminants and BOD was detected. This is as a result of faecal contamination which results in the following health implications; Urinary tract infections, bacteraemia, meningitis, diarrhoea, (one of the main causes of morbidity and mortality among children's), acute renal failure and haemolytic anaemia.

14) Bacteriological parameters-It was observed that some of the sampled wells are without lids and are susceptible to faecal contamination, especially those located within $20 \mathrm{~m}$ radius to dumpsites. The results of microbial tests conducted on these samples are as presented in Table 4 and Figure 12.

\subsection{Health Related Issues on Water in the Study Area Based on the Questionnaire Survey}

For the survey, Alaafia Tayo, Oore-Ofe, Bethel, Favour, Grace, Oyo State Hospital management board, maternity and Ireti-Ayo Hospitals were selected at random in the study area. The survey conducted on the hospitals and the health workers revealed that overall average number of patients often reported daily is 164 . The diseases or ailment often reported are cholera, Typhoid Fever, Diarrhoea, Dysentery, Blue baby syndrome, Malaria, schis- 
Table 4. Results of the DO, BOD and the coliforms.

\begin{tabular}{cccc}
\hline Locations & Dissolved Oxygen mg/l & BOD mg/l & Coliform/litre \\
\hline Ajegunle & 4.3 & 4.19 & 200 \\
Arinkinkin & 3 & 4.28 & 100 \\
Arowomole & 4.5 & 4.31 & 200 \\
Caretaker & 5 & 4.27 & 800 \\
Esanu-Aje & 3.5 & 4.09 & 900 \\
Ita-Olola & 3.2 & 4.09 & 700 \\
Malete & 3.91 & 4.21 & 100 \\
Oke-Alapata & 5.09 & 4.19 & 200 \\
Oora-Gada & 4.02 & 4.27 & 100 \\
Sunsun & 3.71 & 4.18 & 300 \\
\hline
\end{tabular}

tosomia, cancer, carcinogenic diseases. The respondent revealed that the major causes of the aforementioned diseases are; contaminated water, mosquito bites, tsetse flies and poor environmental management.

As shown in Table 5, the respondents revealed that water can cause diseases and that water associated diseases are common in the study area. Figures $\mathbf{1 3}$ to $\mathbf{1 5}$ indicate the results of the responses of the Health Officers on the water-related sicknesses.

1) Turbidity: is a measure of the degree to which the water loses its transparency due to the presence of suspended particulates. It is clearly shown from the results of analysis that sample taken from Esanu-Aje area is highly turbid and the water in the area is said to lose its transparency.

2) Chlorine: This causes environmental harm at low levels. Chlorine is especially harmful to organisms living in water and in soil. Results obtain from the analysis revealed that excessive chloride contents was noticed in Ajegunle, Arowomole, Caretaker, Esanu-Aje, Ita-Olola,

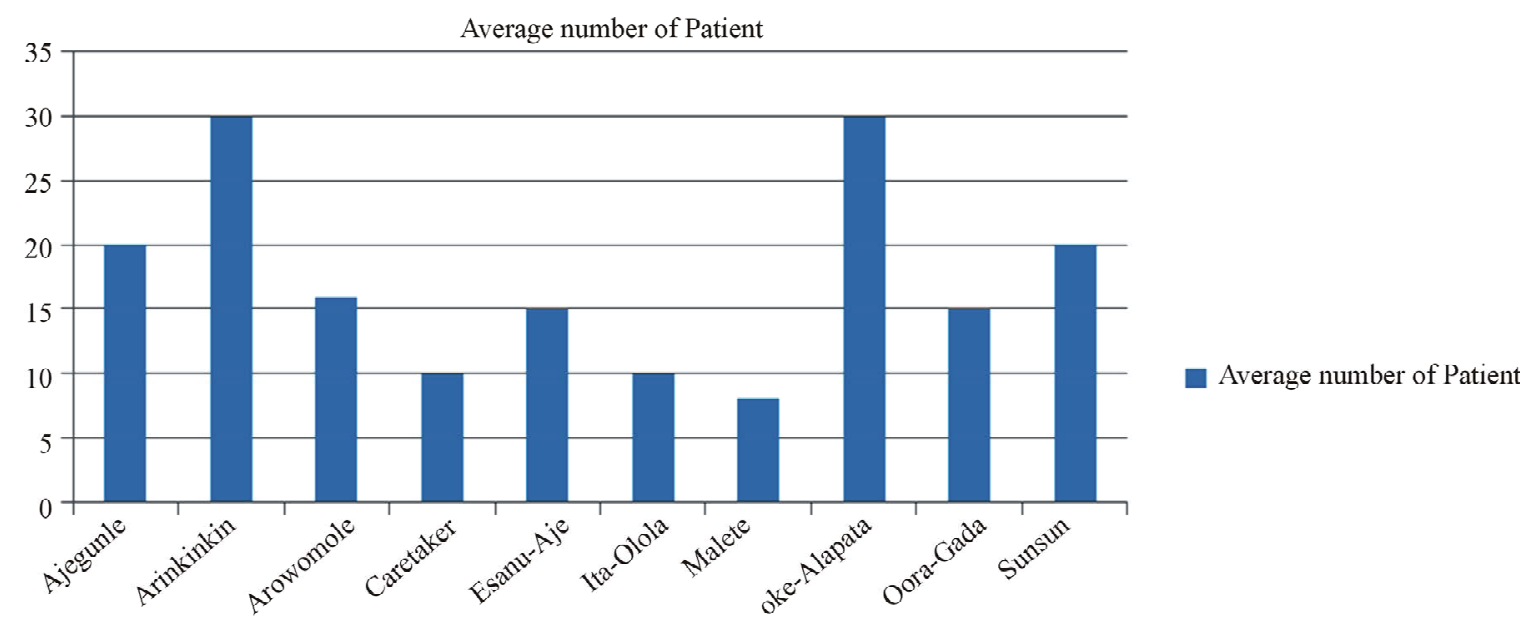

Figure 13. Average number of patient reported by the hospitals in the study area.

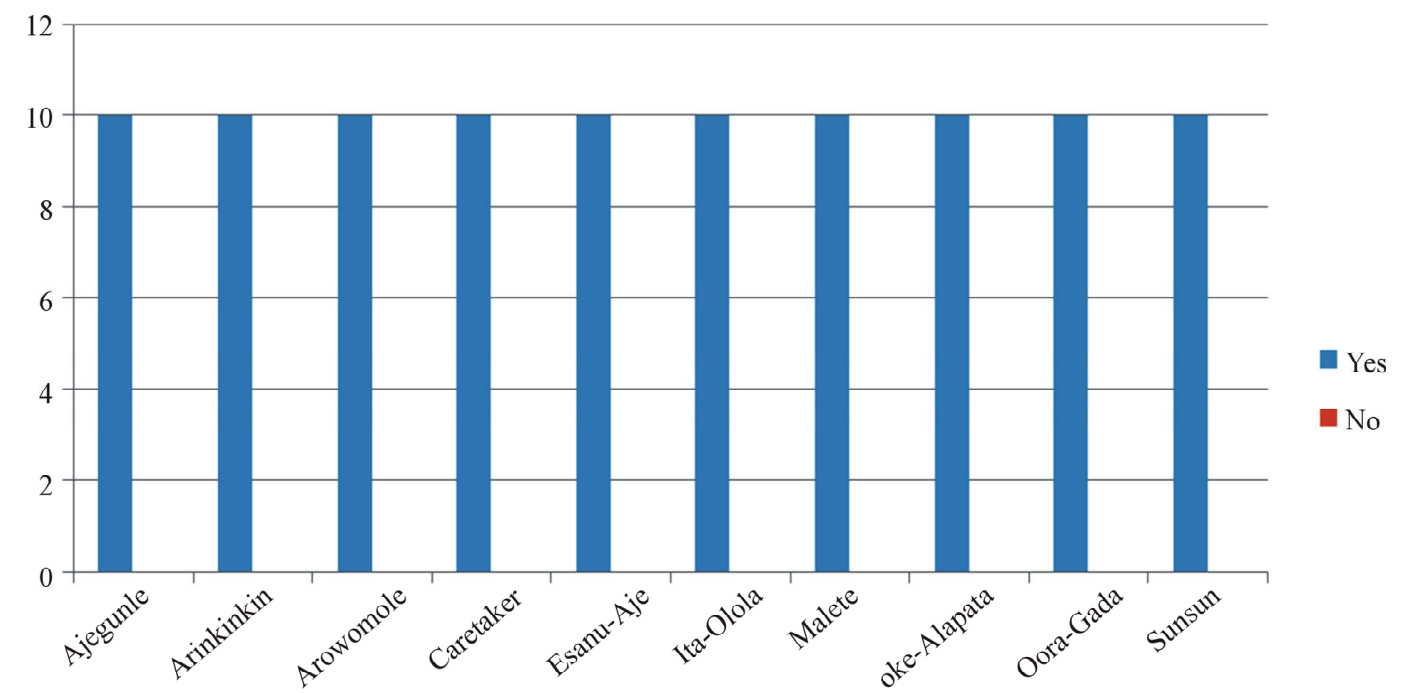

Figure 14. Possibility of water causing diseases. 


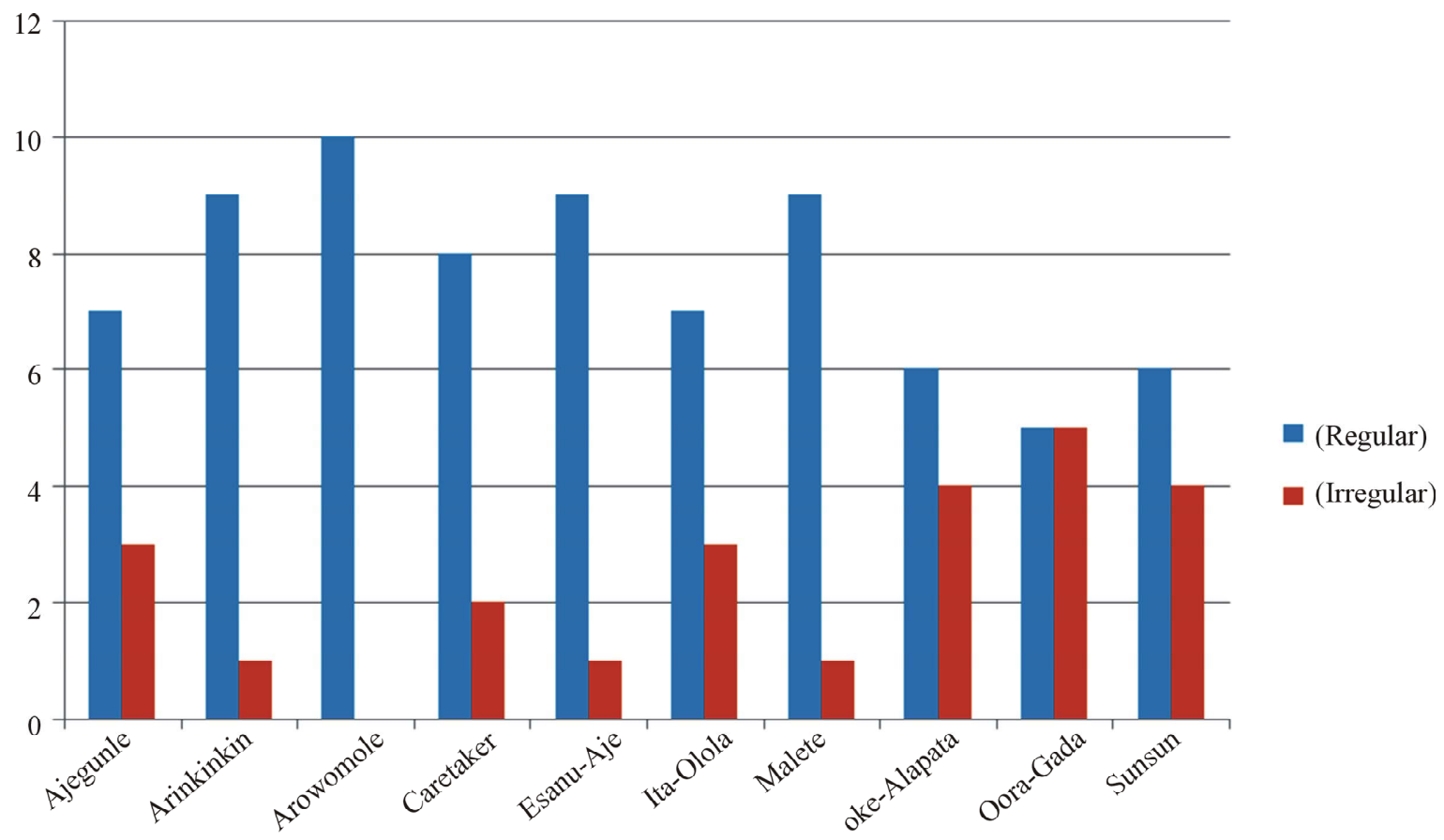

Figure 15. Occurrence of water-related diseases in Ogbomoso.

Table 5. Questionnaire results of health related issues on water in the study area.

\begin{tabular}{|c|c|c|c|c|c|}
\hline \multirow[t]{2}{*}{ Location } & \multicolumn{2}{|c|}{ Can water cause diseases } & \multirow[t]{2}{*}{ Average numbers of patient reported daily } & \multicolumn{2}{|c|}{ Is water associated diseases common in ogbomoso } \\
\hline & Yes & No & & Yes & No \\
\hline Ajegunle & 10 & 0 & 20 & 7 & 3 \\
\hline Arinkinkin & 10 & 0 & 30 & 9 & 1 \\
\hline Arowomole & 10 & 0 & 16 & 10 & 0 \\
\hline Caretaker & 10 & 0 & 10 & 8 & 2 \\
\hline Esanu-Aje & 10 & 0 & 15 & 9 & 1 \\
\hline Ita-Olola & 10 & 0 & 10 & 7 & 3 \\
\hline Malete & 10 & 0 & 8 & 9 & 1 \\
\hline Oke-Alapata & 10 & 0 & 30 & 6 & 4 \\
\hline Oora-Gada & 10 & 0 & 15 & 5 & 5 \\
\hline Sunsun & 10 & 0 & 20 & 6 & 4 \\
\hline
\end{tabular}

Malete, Oke Alapata, Oora-Gada and Sunsun while chloride content observed at Arinkinkin fells within the standard given by WHO.

3) Iron: From the results of the analysis, there is no iron detection in Ajegunle, Arowomole, Arinkinkin, Caretaker, Esanu-Aje, Ita-Olola, Malete, Oke Alapata, Oora-Gada and Sunsun except sample taken from Malete area that was contaminated by iron.

4) Nitrate: The results showed that the sample obtained from Esanu-Aje area has high nitrate contents which exceed the standard given by WHO, NAFDAC and NPDWRs. The uptake of these high concentrations of nitrogen can cause problems in the thyroid gland and it can lead to shortages of vitamin A. In the stomachs and intestines of animals nitrates can convert into nitrosamines, a dangerously carcinogenic kind of substance. Humans have radically changed natural supplies of nitrates and nitrites. The main cause of the addition of nitrates and nitrites is the extensive use of fertilizers. Combustion processes can also enhance the nitrate and nitrite supplies, due to the emission of the nitrogen oxides that can be converted to nitrate and nitrites in the 
environment.

5) Microbiological parameters: The pattern of the coliform levels in the samples is as presented in Figure 12. The measurement was exaggerated as coliform count per litre. The presence of coliform bacteria could be accounted for as a result of faecal contamination of the wells which are not covered. Again a few of the wells were carelessly located downstreams of the septic tanks in residential buildings within a radius of 5 to $10 \mathrm{~m}$. This gives rise to situations whereby traces of coliform were found in the samples thereby posing great health risks to the residents.

\section{Conclusions}

The study reveals that one of the main sources of water supply to the residents of the study area is wells which fall into two categories namely shallow and deep well. The water supply in the study area is not fully supportive to health as some measured parameters have values exceeding those of the standards. The reason for this could be the fetching method through the use of ropes and buckets that exposes the wells to invisible contaminants and pollutants. Also the irregularity in the treatments of the wells is a major threat to the water quality. Waterrelated diseases like amoebic dysentery, typhoid fever, cholera etc. are therefore often reported at the surveyed hospitals.

To abate the problems it is recommended that water for drinking should be subjected to treatment processes like coagulation and filtration to control excess turbidity and total solids, aside boiling. Also, lime softening is also recommended for locations where samples indicate excessive hardness in comparison with the standards. For areas with microbial contaminants, each household should endeavour to disinfect their wells least once in a month. Also, personal hygiene within each household must be improved and always emphasized. There is need for constant surveillance by public health officials to enforce water quality control measures and ensure that water delivered to consumers is at all times safe and potable. The personnel at the waterworks also need to optimize the available resources in terms of funds and equipment. Each component of water supply system from source through treatment process storage and distribution must be ascertained functioning well time to time without any risks or failure.

\section{REFERENCES}

[1] A. O. Olaniran and P. A. Oluwande, "Environmental and Health,” Nigerian Conservation Foundation, Vol. 3. No. 4, 1995, pp. 18-25.

[2] P. A. Oluwande, "A Guide to Tropical Environment Health and Engineering,” National Institute of Science Education and Research, Ibadan, 1983, pp. 5-84.

[3] O. Oyebande and A. Akinwale, “Nigeria's Ground Water Resources-Extent, Value and Use," Ultimate Water Technology, Vol. 1, No. 1, 1996, pp. 41-45.

[4] P. Morgan, "Drinking Water, Quality for Rural Areas," Macmillan Publishers, Ibadan, 1990, pp. 248-252.

[5] D. A. Aremu, "Impact of Petroleum Operation on Ground Water Quality in Warri,” M.S. Thesis, University of Ibadan, Ibadan, 1988, pp. 45-56.

[6] S. O. Ojoawo, O. A. Agbede and A. Y. Sangodoyin, “Contamination Effects of Dumpsite Wastes on Surface and Groundwater Resource of Ogbomoso Local Government Areas," LAUTECH Journal of Engineering and Technology, Vol. 6, No. 1, 2010, pp. 92-99.

[7] J. O. Obemaeta, "Water Preservation and Treatment in: Water and Building Sanitation," Claverium Press, Ibadan, 1991, pp. 20-41.

[8] D. Chapman and V. Hall, "The Selection of Water Quality Variables,” In: A Guide to the Use of Biota, Sediments and Water in Environmental Monitoring, World Health Organization, Geneva, 1987, p. 40.

[9] E. A. Albert, "Chemical Composition of Bottled Mineral Water," Archive of Environmental Health, Vol. 44, No. 2, 1987, p. 6.

[10] USEPA, "Health Advisory Summaries on Water," Office of Water, United States Environmental Protection Agency, Ohio, 2012, p. 23.

[11] WHO, “Guidelines for Drinking Water,” World Health Organization, Geneva, 2011, p. 45.

[12] NPC, "Population Figures," National Population Commission, Abuja, 2006, p. 5.

[13] S. Cairncross and R. G. Feachem, "Environmental Health Engineering in the tropics: An Introductory Text," 2nd Edition, John Wiley, Chichester, 1997, p. 35.

[14] NAFDAC, “Consumer Safety Bulletin,” National Agency for Food and Drug Administration and Control, Abuja, 2001, p. 7. 